Research Article

\title{
Study on the Axial Compression Postbuckling Similitude Model of the Stiffened Cylindrical Shell with Dimple Imperfections
}

\author{
Jiawei Ding $\left(\mathbb{D},{ }^{1}\right.$ Xinkui Xing $\mathbb{D}^{1,2}$ Wei Yu $\mathbb{D}^{1,2}$ and Wanxu Zhu $\mathbb{D}^{1,2}$ \\ ${ }^{1}$ College of Civil and Architecture Engineering, Guilin University of Technology, Guilin 541004, China \\ ${ }^{2}$ Guangxi Key Laboratory of New Energy and Building Energy Saving, Guilin 541004, China \\ Correspondence should be addressed to Wei Yu; yuwei3601@163.com
}

Received 23 November 2020; Revised 20 March 2021; Accepted 2 April 2021; Published 20 April 2021

Academic Editor: Daniele Baraldi

Copyright (c) 2021 Jiawei Ding et al. This is an open access article distributed under the Creative Commons Attribution License, which permits unrestricted use, distribution, and reproduction in any medium, provided the original work is properly cited.

The body of the new-type dry gas holder is a large stiffened cylindrical shell. Limited by the test site and economic conditions, the buckling characteristics of such holders are generally studied through scale model experiments. Taking the longitudinal-ring rectangular stiffened cylindrical shell as the research object, the generalized similitude condition and scaling principle formula of the structure are derived innovatively based on Donnell's assumption and the energy method. By means of displacement loading and node coordinates updating, dimple imperfections are introduced into the ideal structure of the stiffened cylindrical shell, and then, the complete similitude and partial similitude analysis of axial compression nonlinear buckling for imperfect structures are carried out. The analysis results show that the complete similitude analysis of stiffened cylindrical shell axial-compression nonlinear buckling can be realized accurately; the partial similitude model for stiffened cylindrical shell axial-compression nonlinear buckling can better predict the buckling characteristics of its prototype structures, and the closer the Poisson's ratio between the model and the prototype materials is, the more accurate the prediction results are. Meanwhile, the generalized similitude condition and scaling principle formula derived based on the energy method can provide useful reference for the model design and experimental verification of the axial compression buckling of the stiffened cylindrical shell with local geometric imperfections.

\section{Introduction}

Stiffened thin-walled cylindrical shell is usually composed of skin and ribs, which have the advantages of high specific stiffness and specific strength, so it is widely used in aerospace, ships and vessels, pressure vessels, and other structures [1]. Stiffened thin-walled cylindrical shell structures in engineering usually contain geometric imperfections, and as a result, such structures are prone to buckling failure. Due to the limitation of high cost, difficulty, and long time in the prototype buckling test for large-size stiffened thin-walled cylindrical shell structures, the results of the scale model buckling test are usually used to predict the buckling characteristics of prototype structures [2].

Scholars at home and abroad have made some progress in studying the buckling and buckling scale model of shells. The main methods include dimensional analysis, similitude transformation analysis based on the solution of the shell governing equation, and similitude transformation analysis based on the structural system governing the differential equation as well as the energy method. Simitses et al. [3] have carried out studies on laminated cylindrical shell axial-compression buckling scale models. The results show that the radius, length, and thickness of the shell are important parameters that affect the design of the scale model. Laminated cylindrical shells can realize partial similitude simulation of geometric dimension scaling, but when the materials are different, the model cannot accurately predict the prototype. Ungbhakorn and Singhatanadgid $[4,5]$ have also carried out the research on the complete similitude and partial similitude scaling principles for the buckling of laminated cylindrical shells. When the materials of the model and the prototype are different, the model still cannot predict the 
buckling characteristics of the prototype. Hilburger et al. $[6,7]$ have obtained more accurate ultimate buckling load of the structure with the stiffened cylindrical shell finite element model verified by the scale model test and prototype test. This method does not need to carry out a large number of tests on large-size stiffened cylindrical shells, but the author has not given the basis for designing the scale model and the buckling scaling principle formula. Balbin and Bisagni [8] have presented a scaling method for sandwich composite cylindrical shells based on the nondimensionalization buckling equations. The results of the finite element show that the agreement is better in the case in which there is a lower transverse shear influence between the prototype and the model. Based on the energy method, Yu [9] has derived the complete and partial similitude scaling principle formula for the buckling of stiffened cylindrical shells under axial compression and lateral compression and verified the accuracy of the formula by finite element simulation but has not studied the structural similitude of stiffened cylindrical shells with dimple imperfections.

Basically speaking, there always exist some initial geometric imperfections in the shell structure in practical engineering. In recent years, many scholars have carried out further research in the field about shell buckling and imperfection sensitivity analysis. Tian and Wang [10] have proposed a method for accurate determination of compressive response of axially loaded stiffened shells based on the Worst Multiple Perturbation Load Approach. The results show that the proposed method is efficiencient to predict lower-bound buckling loads for stiffened shells. Wagner et al. [11] have presented a new design lower bound for metallic orthogonal-stiffened shells under axial compression. The analysis results of the shell with multiple cutouts and the perfect shell were compared and analyzed. Based on proper orthogonal decomposition and vibration correlation technique, Tian et al. [12] proposed the POD-VCT analysis method for imperfect shells under axial compression and verified the reliability of the method by buckling tests of shells with different structural configurations, materials, and imperfections. Among the imperfections, dimple imperfection is one of the most typical and unfavorable initial geometric imperfections [13]. Therefore, it is of great significance to study the axial compression buckling scale model of the stiffened cylindrical shell with dimple imperfections. In this paper, taking the longitudinal-ring rectangular stiffened cylindrical shell as the research object and based on the densely stiffening theory and energy method, the generalized similitude conditions and scaling principle formula of the structure are put forward, and the complete similitude and partial similitude simulation analysis of the nonlinear buckling of the structure under axial compression are carried out. Using the dimple imperfection function, dimple imperfection is introduced into the finite element model of perfect stiffened cylindrical shells. Furthermore, the nonlinear buckling similitude analysis of the prototype and scale model of the stiffened cylindrical shell with dimple imperfections is carried out to verify the generalized similitude conditions of the scale model design and the scaling principle formula of nonlinear buckling under axial compression.

\section{Buckling Scaling Principle Formula of the Longitudinal-Ring Stiffened Cylindrical Shell under Axial Compression}

The mathematical models of arbitrary two similar stiffened cylindrical shell structures are consistent in the process of similitude transformation, and their total energy relationship is [14]

$$
\Pi_{p}\left(X_{p i}\right)=\Psi\left(C_{i}\right) \Pi_{m}\left(X_{m i}\right)
$$

where the prototype and model are distinguished by subscripts $p$ and $m, X_{p i}$ and $X_{m i}$ correspond to the material and geometric parameters of the prototype and model, respectively, $C_{i}$ represents the scaling factor of the structural parameters of the prototype and model, and $\Psi\left(C_{i}\right)$ represents the transfer function of the scaling factors of two similar structures. This relational expression can be used to derive the generalized similitude conditions and the scaling principle formula for the buckling of stiffened cylindrical shells under axial compression.

The energy functional of the stiffened cylindrical shell under static force can be expressed as

$$
\Pi=U+U_{L}
$$

where $U$ and $U_{L}$ are the strain energy and external work of the structure, respectively.

Based on Donnell's assumption, the nonlinear geometric equation of the middle plane of the stiffened cylindrical shell with initial geometric imperfections is [15]

$$
\begin{aligned}
\varepsilon_{x} & =u_{, x}+\frac{1}{2}\left(w_{, x}\right)^{2}+w_{, x} \bar{w}_{, x}, \\
\varepsilon_{y} & =v_{, y}+\frac{w}{R}+\frac{1}{2}\left(w_{, y}\right)^{2}+w_{, y} \bar{w}_{, y}, \\
\gamma_{x y} & =u_{, y}+v_{, x}+w_{, x} w_{, y}+w_{, x} \bar{w}_{, y}+\bar{w}_{, x} w_{, y}, \\
\chi_{x} & =-w_{, x x}, \\
\chi_{y} & =-w_{, y y}, \\
\chi_{x y} & =-w_{, x y},
\end{aligned}
$$

where $\varepsilon_{x}, \varepsilon_{y}$, and $\gamma_{x y}$ represent the axial strain, circumferential strain, and shear strain of the cylindrical shell, respectively, $\chi_{x}, \chi_{y}$, and $\chi_{x y}$ represent the curvature of the cylindrical shell, and $u, v, w$, and $\bar{w}$ represent the axial, circumferential, and radial displacements and the radial displacement imperfections of the cylindrical shell, respectively.

The internal force expression of the stiffened cylindrical shell based on densely stiffening theory is [16] 


$$
\begin{aligned}
N_{x} & =A_{11} \varepsilon_{x}+A_{12} \varepsilon_{x y}+B_{11} \chi_{x}, \\
N_{y} & =A_{12} \varepsilon_{x}+A_{22} \varepsilon_{x y}+B_{22} \chi_{y}, \\
N_{x y} & =A_{66} \gamma_{x y}, \\
M_{x} & =B_{11} \varepsilon_{x}+D_{11} \chi_{x}+D_{12} \chi_{y}, \\
M_{y} & =B_{22} \varepsilon_{y}+D_{12} \chi_{x}+D_{22} \chi_{y}, \\
M_{x y} & =D_{66} \chi_{x y},
\end{aligned}
$$

where $N_{x}, N_{y}$, and $N_{x y}$ represent membrane internal forces per unit length, $M_{x}, M_{y}$, and $M_{x y}$ represent bending moments per unit length, and $A_{i j}, B_{i j}$, and $D_{i j}$ represent tensile stiffness, coupled stiffness, and bending stiffness, respectively. The expressions of these stiffness parameters are

$$
\begin{aligned}
& A_{11}=B+\frac{E_{s} A_{s}}{d_{s}}, \\
& A_{12}=\mu B, \\
& A_{22}=B+\frac{E_{r} A_{r}}{d_{r}}, \\
& A_{66}=\frac{1-\mu}{2} B, \\
& B_{11}=e_{s} \frac{E_{s} A_{s}}{d_{s}}, \\
& B_{22}=e_{r} \frac{E_{r} A_{r}}{d_{r}}, \\
& D_{11}=D+\frac{E_{s} I_{s}}{d_{s}}, \\
& D_{12}=\mu D, \\
& D_{22}=D+\frac{E_{r} I_{r}}{d_{r}}, \\
& D_{66}=D(1-\mu)+\frac{1}{2}\left(\frac{G_{s} J_{s}}{d_{s}}+\frac{G_{r} J_{r}}{d_{r}}\right),
\end{aligned}
$$

where subscripts $s$ and $r$ represent longitudinal and circumferential stiffeners, respectively, $E, \mu$, and $G$ represent the elasticity modulus, Poisson's ratio, and shear modulus of the material, respectively, $B$ and $D$ represent the tensile stiffness and bending stiffness of the skin, respectively, $A_{r}$ and $A_{s}$ represent the cross-sectional area of stiffeners, $e_{r}$ and $e_{s}$ represent the eccentricity of stiffeners relative to the middle plane of the shell, $I_{r}$ and $I_{s}$ represent the inertia moment of stiffeners relative to the middle plane of the shell, $d_{r}$ and $d_{s}$ represent the distance between two adjacent stiffeners, and $J_{r}$ and $J_{s}$ represent the torsion constants of stiffeners.

The expression of the strain energy and external work of the stiffened cylindrical shell is $[17,18]$

$$
\begin{aligned}
U= & \frac{1}{2} \int_{0}^{2 \pi R} \int_{0}^{L}\left(N_{x} \varepsilon_{x}+N_{x y} \gamma_{x y}+N_{y} \varepsilon_{y}+M_{x} \chi_{x}\right. \\
& \left.+2 M_{x y} \chi_{x y}+M_{y} \chi_{y}\right) \mathrm{d} x \mathrm{~d} y, \\
U_{L}= & -\int_{0}^{2 \pi R} \int_{0}^{L} p_{x} u_{, x} \mathrm{~d} x \mathrm{~d} y,
\end{aligned}
$$

where $L$ and $R$ represent the axial length and radius of the cylindrical shell, respectively, and $p_{x}$ represents the axial load of the structure.

From formulas (2)-(7), we can obtain the total energy of the densely stiffened cylindrical shell, which is

$$
\begin{aligned}
\Pi= & \frac{1}{2} \int_{0}^{2 \pi R} \int_{0}^{L}\left\{A_{11}\left[u_{, x}+\frac{1}{2}\left(w_{, x}\right)^{2}+w_{, x} \bar{w}_{, x}\right]^{2}+A_{22}\left[v_{, y}+\frac{w}{R}+\frac{1}{2}\left(w_{, y}\right)^{2}+w_{, y} \bar{w}_{, y}\right]^{2}\right. \\
& +2 A_{12}\left[u_{, x}+\frac{1}{2}\left(w_{, x}\right)^{2}+w_{, x} \bar{w}_{, x}\right] \times\left[v_{, y}+\frac{w}{R}+\frac{1}{2}\left(w_{, y}\right)^{2}+w_{, y} \bar{w}_{, y}\right] \\
& +A_{66}\left(u_{, y}+v_{, x}+w_{, x} w_{, y}+w_{, x} \bar{w}_{, y}+\bar{w}_{, x} w_{, y}\right)^{2}-2 B_{11} w_{, x x}\left[u_{, x}+\frac{1}{2}\left(w_{, x}\right)^{2}+w_{, x} \bar{w}_{, x}\right] \\
& -2 B_{22} w_{, y y}\left[v_{, y}+\frac{w}{R}+\frac{1}{2}\left(w_{, y}\right)^{2}+w_{, y} \bar{w}_{, y}\right]+D_{11} w_{, x x} w_{, x x}+2 D_{12} w_{, x x} w_{, y y} \\
& \left.+D_{22} w_{, y y} w_{, y y}+2 D_{66} w_{, x y} w_{, x y}-2 p_{x} u_{, x}\right\} \mathrm{d} x \mathrm{~d} y .
\end{aligned}
$$


When the geometric parameters of the skin with two similar structures are completely similar, then $C_{x}=C_{y}=$ $C_{u}=C_{v}=C_{w}=C_{R}$. According to conversion formula (1) of total energy similitude between the scale model and prototype structure, the necessary condition for similitude between the scale model and prototype structure can be obtained, which is

$$
\begin{aligned}
C_{A_{11}} & =C_{A_{12}}=C_{A_{22}}=C_{A_{66}}=\frac{C_{B_{11}}}{C_{R}}=\frac{C_{B_{22}}}{C_{R}}=\frac{C_{D_{11}}}{C_{R}^{2}} \\
& =\frac{C_{D_{12}}}{C_{R}^{2}}=\frac{C_{D_{22}}}{C_{R}^{2}}=\frac{C_{D_{66}}}{C_{R}^{2}}=C_{p_{x}} .
\end{aligned}
$$

According to formula (9), the similar invariant of the buckling of the densely stiffened cylindrical shell under axial compression can be obtained, which is

$$
\frac{C_{\bar{p}_{x}} \cdot C_{R}^{2}}{C_{\text {stiff }}}=1,
$$

where $\bar{p}_{x}$ represents the axial buckling load of the stiffened cylindrical shell, $C_{\text {stiff }}=C_{A_{i j}} C_{R}^{2}=C_{B_{i j}} C_{R}=C_{D_{i j}}$.

Therefore, the scaling principle formula for the buckling of densely stiffened cylindrical shells under axial compression can be written as

$$
\left(\bar{p}_{x}\right)_{p}=\left(\bar{p}_{x}\right)_{m} \frac{C_{\text {stiff }}}{C_{R}^{2}}=\left(\bar{p}_{x}\right)_{m} \cdot C_{\text {stiff }}\left(\frac{R_{m}}{R_{p}}\right)^{2} .
$$

\section{Verification of Nonlinear Buckling of the Cylindrical Shell with Dimple Imperfections under Axial Compression by the Finite Element Example}

In this paper, the example for nonlinear buckling of the cylindrical shell with dimple imperfections under axial compression in literature [19] is taken as the example for verification by using finite element software ANSYS, and the finite element APDL language program of the example is written to verify the accuracy and reliability of the finite element analysis in this paper. The geometric and material parameters of the cylindrical shell with dimple imperfections are shown in Table 1. The upper boundary of the structure only releases the axial displacement constraint, while the lower boundary of the structure adopts the fixed end boundary.

The applied dimple imperfection function is [19]

$$
\begin{aligned}
\delta_{a}(s) & =\delta_{0} e^{-\pi s / \lambda} \cos \frac{\pi s}{\lambda}, \\
s & =\sqrt{\left(R \theta-R \theta_{0}\right)^{2}+\left(z-z_{0}\right)^{2}},
\end{aligned}
$$

where $\lambda$ is the imperfection diameter, $\delta_{0}$ is the imperfection amplitude, $\theta_{0}$ and $z_{0}$ are the circumferential and axial coordinate values of the imperfection center, and $s$ is the distance from the finite element grid node to the imperfection center within the imperfection range. The dimple
TABLE 1: Geometric and material parameters of the cylindrical shell.

\begin{tabular}{lcccc}
\hline Material parameters & \multicolumn{3}{c}{$\begin{array}{c}\text { Geometric parameters of } \\
\text { cylindrical shell }(\mathrm{m})\end{array}$} \\
$E(\mathrm{GPa})$ & $\mu$ & $R$ & $L$ & $t$ \\
\hline 72 & 0.31 & 0.25 & 0.51 & 0.0005 \\
\hline
\end{tabular}

imperfection is introduced into the perfect structural model by static analysis of displacement loading and updating the node coordinates of the model.

Newton-Raphson method (NR method) with displacement loading and arc-length method (AR method) with force loading are used for example verification. Figure 1 shows the comparison between the load-displacement curves of the perfect structural buckling under axial compression analyzed by two methods and the literature results. Table 2 lists the errors between the results obtained by the two methods and the literature results when $\delta_{0}=5 t$ and $\lambda$ are $0.05 \mathrm{~m}, 0.06 \mathrm{~m}$, and $0.07 \mathrm{~m}$, respectively.

It can be seen from Figure 1 and Table 2 that the arclength method APDL program for nonlinear buckling analysis of cylindrical shells under axial compression is accurate and reliable.

\section{Complete Similitude Analysis of Nonlinear Buckling of the Longitudinal-Ring Rectangular Stiffened Cylindrical Shell under Axial Compression}

4.1. Scaling Principle Formula for Complete Similitude of Nonlinear Buckling of the Longitudinal-Ring Rectangular Stiffened Cylindrical Shell under Axial Compression. Under the condition of complete similitude, the geometric dimension scaling factors, material parameters, and boundary conditions of the prototype and model are identical. When the geometric scaling factor of the model is $k$, the stiffness scaling factor of the structure is

$$
\begin{gathered}
C_{A_{i j}}=k, \\
C_{B_{i j}}=k^{2}, \\
C_{D_{i j}}=k^{3}, \\
C_{\text {stiff }}=k^{3} .
\end{gathered}
$$

Therefore, scaling principle formula (11) for the buckling of the densely stiffened cylindrical shell under axial compression can be simplified as

$$
C_{\bar{p}_{x}}=k \text {. }
$$

4.2. Example Analysis on Complete Similitude of Nonlinear Buckling of the Longitudinal-Ring Rectangular Stiffened Cylindrical Shell under Axial Compression. Based on finite element software ANSYS, the shell 181 element is utilized to discretize the model. See Tables 3 and 4 for parameters of the prototype and model of the longitudinal-ring stiffened 


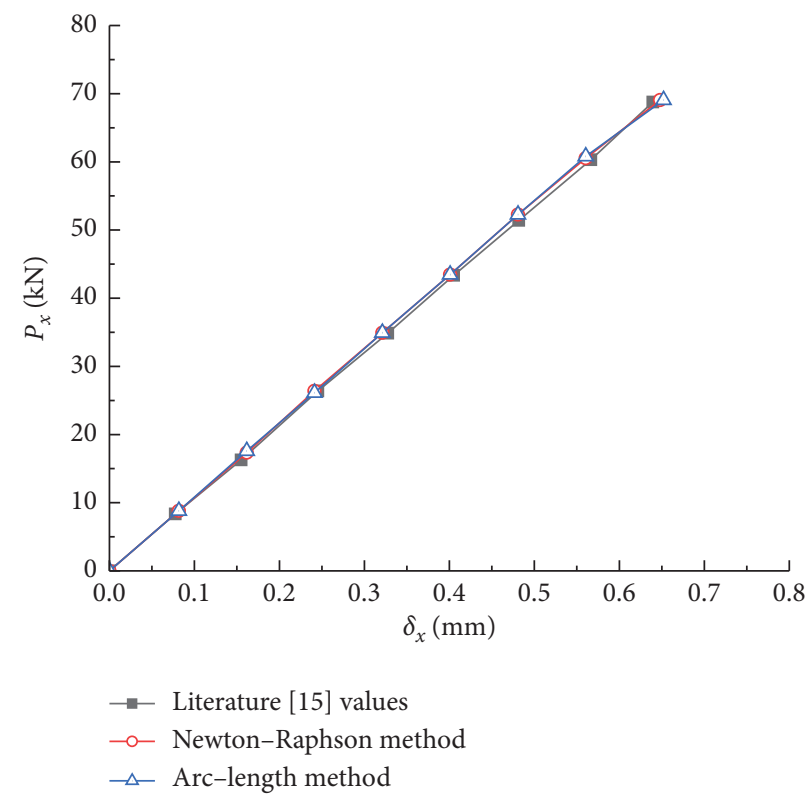

Figure 1: Comparison of axial compression buckling load axial-compression deformation curves of the perfect cylindrical shell.

TABLE 2: Comparison of nonlinear buckling ultimate loads of cylindrical shells with dimple imperfections under axial compression.

\begin{tabular}{ccccccc}
\hline$\delta_{0}(\mathrm{~m})$ & $\lambda(\mathrm{m})$ & Literature [15] $(\mathrm{kN})$ & NR method $(\mathrm{kN})$ & Error $(\%)$ & AR method $(\mathrm{kN})$ & Error $(\%)$ \\
\hline \multirow{2}{*}{$0.5 t$} & 0.05 & 42.18 & 44.37 & 5.19 & 43.90 \\
& 0.06 & 42.29 & 43.41 & 2.65 & 44.04 & 4.08 \\
& 0.07 & 42.38 & 44.49 & 4.98 & 43.96 \\
\hline
\end{tabular}

TABLE 3: Parameters of the longitudinal-ring stiffened cylindrical shell prototype.

\begin{tabular}{cccccccccc}
\hline $\begin{array}{c}\text { Material } \\
\text { parameters }\end{array}$ & \multicolumn{3}{c}{ Geometric parameters of skin } \\
$(\mathrm{m})$
\end{tabular}

TABLe 4: Parameters of the completely similar model of the longitudinal-ring stiffened cylindrical shell.

\begin{tabular}{ccccccccccc}
\hline \multicolumn{2}{c}{$\begin{array}{c}\text { Material } \\
\text { parameters }\end{array}$} & \multicolumn{3}{c}{ Geometric parameters of skin $(\mathrm{m})$} & \multicolumn{5}{c}{ Stiffeners parameters } \\
$E(\mathrm{GPa})$ & $\mu$ & $R_{\mathrm{m}}$ & $L_{\mathrm{m}}$ & $t_{\mathrm{m}}$ & $h_{\mathrm{sm}}(\mathrm{mm})$ & $t_{\mathrm{sm}}(\mathrm{mm})$ & $N_{\mathrm{sm}}$ & $h_{\mathrm{rm}}(\mathrm{mm})$ & $t_{\mathrm{rm}}(\mathrm{mm})$ & $N_{\mathrm{rm}}$ \\
\hline 72.40 & 0.3 & 0.24257 & 0.60885 & 0.00127 & 3.8354 & 2.4384 & 60 & 3.8354 & 2.4384 & 24 \\
\hline
\end{tabular}

Note. $t$-skin thickness, $h_{\mathrm{r}}$ and $h_{\mathrm{s}}$-height of rectangular stiffeners, $t_{\mathrm{r}}$ and $t_{\mathrm{s}}$-thickness of rectangular stiffeners, and $N_{\mathrm{r}}$ and $N_{\mathrm{s}}$-number of stiffeners.

cylindrical shell. The geometric scaling factors of scale models are all taken as 10. In order to ensure the accuracy and economy of finite element simulation, reasonable unit partition is made for both the prototype and model. For the model and prototype of the longitudinal-ring stiffened cylindrical shell, the interval between two adjacent stiffeners is divided into 8 equal parts, and the height of the stiffening web is divided into 3 equal parts. Use the dimple imperfection function expressed by formulae (12a) and (12b) to introduce dimple imperfection into the longitudinal-ring stiffened cylindrical shell, with the dimple imperfection center located at half of the height of the cylindrical shell. Use the arc length method in finite element analysis to study the complete similitude of the nonlinear buckling of the longitudinal-ring stiffened cylindrical shell under axial compression. The finite element model of the longitudinalring stiffened cylindrical shell with dimple imperfection is shown in Figure 2.

Table 5 shows the comparison of critical load buckling of the longitudinal-ring rectangular stiffened cylindrical shell under axial compression. It can be seen from Table 5 that, under the nine working conditions consisting of three imperfection amplitudes and three imperfection diameters, the absolute value of the relative error between the critical load of the prototype structure predicted by the scale model based on scaling principle formula (14) and the critical load 


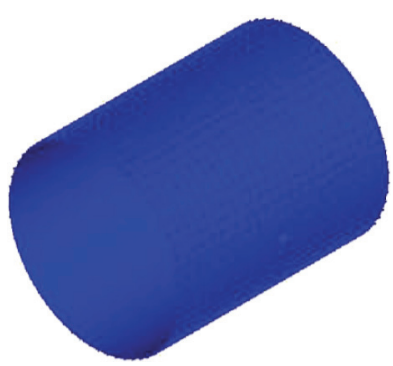

(a)

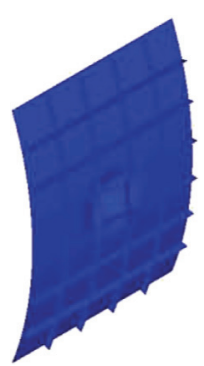

(b)

FiguRe 2: Longitudinal-ring stiffened cylindrical shell finite element model with dimple imperfection introduced (3x magnification).

TABLE 5: Complete similitude simulation of nonlinear buckling of longitudinal-ring rectangular stiffened cylindrical shell under axial compression.

\begin{tabular}{|c|c|c|c|c|c|c|}
\hline \multirow[b]{2}{*}{$\delta_{0}(\mathrm{~m})$} & \multicolumn{3}{|c|}{ Model } & \multicolumn{2}{|c|}{ Prototype } & \multirow[b]{2}{*}{ Error (\%) } \\
\hline & $\lambda(\mathrm{m})$ & $\begin{array}{l}\text { Critical buckling } \\
\text { load } / \mathrm{kN} \cdot \mathrm{m}^{-1}\end{array}$ & $\lambda(\mathrm{m})$ & $\begin{array}{l}\text { Critical buckling } \\
\text { load }\left(\mathrm{kN} \cdot \mathrm{m}^{-1}\right)\end{array}$ & $\begin{array}{l}\text { Critical buckling load for predicted } \\
\text { prototype }\left(\mathrm{kN} \cdot \mathrm{m}^{-1}\right)\end{array}$ & \\
\hline \multirow{3}{*}{$0.1 \bar{t}$} & 0.048 & 715.790 & 0.480 & 7090.300 & 7157.900 & 0.950 \\
\hline & 0.060 & 631.083 & 0.600 & 6224.060 & 6310.830 & 1.390 \\
\hline & 0.072 & 592.084 & 0.720 & 5985.940 & 5920.840 & -1.080 \\
\hline \multirow{3}{*}{$0.3 \bar{t}$} & 0.048 & 683.33 & 0.480 & 6780.880 & 6833.300 & 0.770 \\
\hline & 0.060 & 515.110 & 0.600 & 5273.950 & 5151.100 & -2.320 \\
\hline & 0.072 & 489.879 & 0.720 & 4895.220 & 4898.790 & 0.070 \\
\hline \multirow{3}{*}{$0.5 \bar{t}$} & 0.048 & 642.638 & 0.480 & 6382.980 & 6426.380 & 0.680 \\
\hline & 0.060 & 483.181 & 0.600 & 4810.450 & 4831.810 & 0.440 \\
\hline & 0.072 & 448.419 & 0.720 & 4476.690 & 4484.190 & 0.170 \\
\hline
\end{tabular}

Note. $\bar{t}$ is the sum of the thickness of the cylindrical shell skin and the height of stiffeners.

of the prototype structure is within $2.500 \%$, which indicates that the complete similitude of nonlinear buckling of the stiffened cylindrical shell with dimple imperfections under axial compression can be realized accurately.

Figures 3(a) and 3(b), respectively, show the relationship between the critical loads and the imperfection amplitudes and diameters of the prototype and the model. It can be seen that the critical loads of the prototype and the model decrease with the increase of imperfection amplitude and diameter.

Figure 4 shows the comparison of load-displacement curves of the structural prototype, model, and the prediction prototype under three kinds of imperfection amplitudes when the imperfection diameters of the prototype and model are $0.720 \mathrm{~m}$ and $0.072 \mathrm{~m}$, respectively. It can be seen from Figure 4 that the load-displacement curve of the complete similitude scale model can accurately predict the load-displacement curve of the prototype.

Figure 5 shows the displacement vector and nephogram of the structural prototype and the complete similitude scale model at the point corresponding to the critical load when the imperfection diameter of the prototype and the model is $0.720 \mathrm{~m}$ and $0.072 \mathrm{~m}$, respectively, and the imperfection amplitude is $0.5 \bar{t}$. From Figure 5, it can be seen that the buckling modes of the model and the prototype are the same at the point corresponding to the critical load.

\section{Partial Similitude Analysis of Axial Compression Nonlinear Buckling of the Longitudinal-Ring Rectangular Stiffened Cylindrical Shell}

5.1. Partial Similitude Scaling Principle Formula for Axial Compression Nonlinear Buckling of the Longitudinal-Ring Stiffened Cylindrical Shell. It is extremely difficult to satisfy all the similitude conditions, and it is not applicable in practical engineering, so it is necessary to carry out studies on the partial similitude model. In this paper, considering the situation that the materials and geometric dimensions of the scale model are different from those of the prototype, aluminum (Al), copper, brass, and plastic (PVC) are used, respectively, as the materials for the scale model. The material parameters are shown in Table 6.

Taking the ratio of elastic modulus between the prototype and model as $k$ and the scaling factor of skin geometric dimension as $k_{1}$, then there is a similitude relation as follows:

$$
C_{E}=k, C_{R}=C_{L}=C_{t}=C_{d_{\mathrm{r}}}=C_{d_{\mathrm{s}}}=k_{1} .
$$

Substituting formula (15) into necessary similitude condition formula (9) and similitude invariant formula (10), we can get 


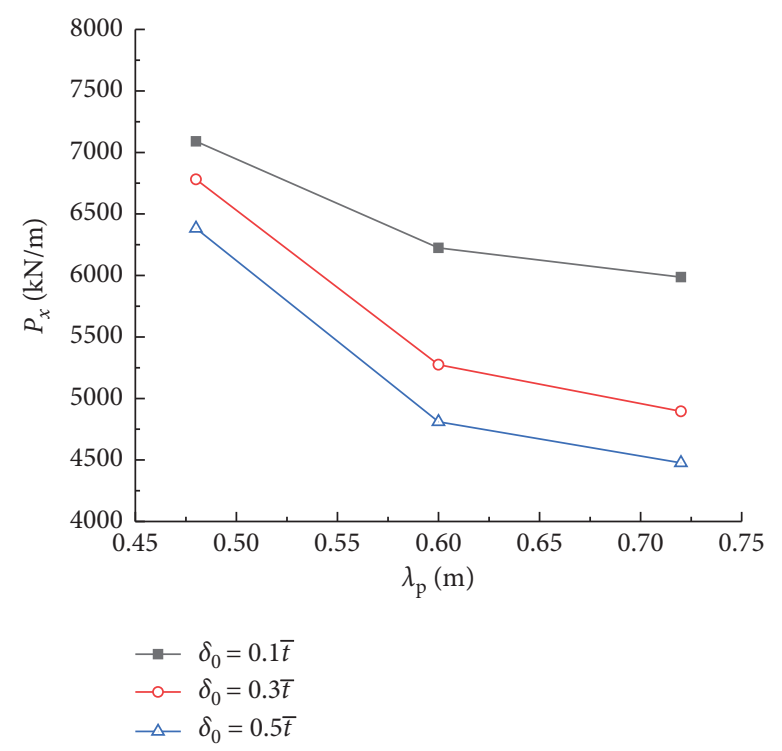

(a)

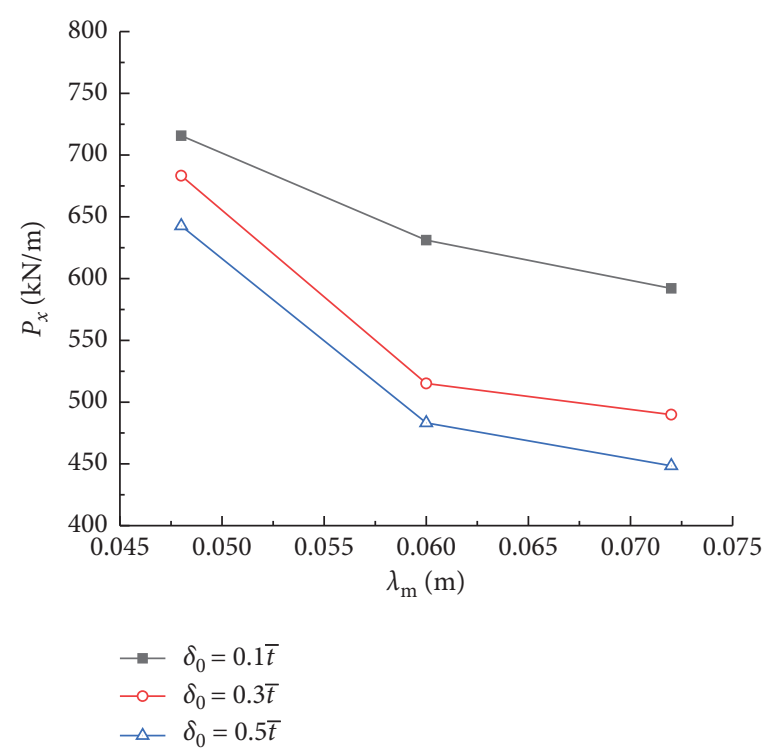

(b)

FIGURE 3: Imperfection sensitivity of the prototype and model under different imperfection diameters and amplitudes. (a) Prototype. (b) Model.

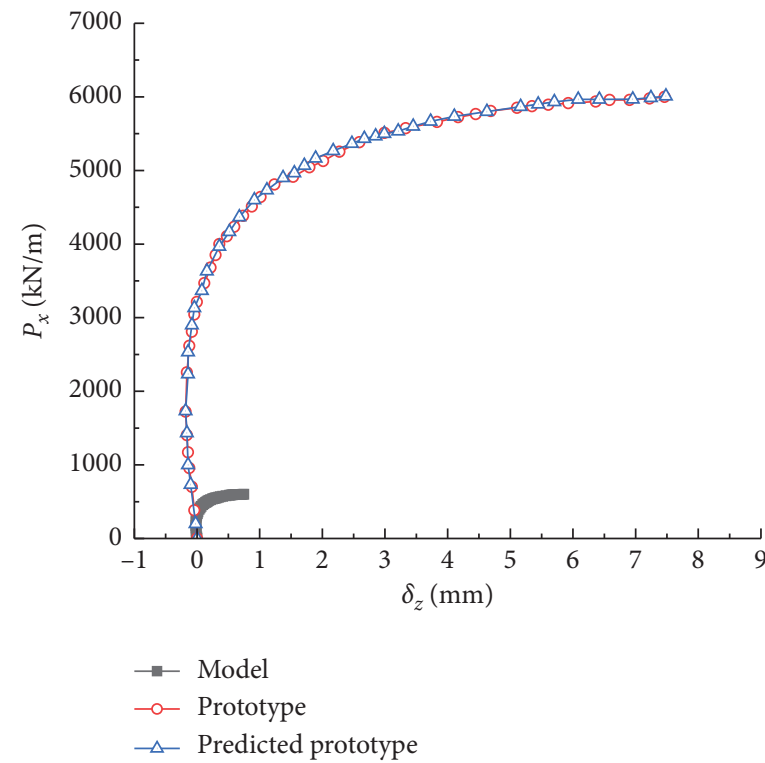

(a)

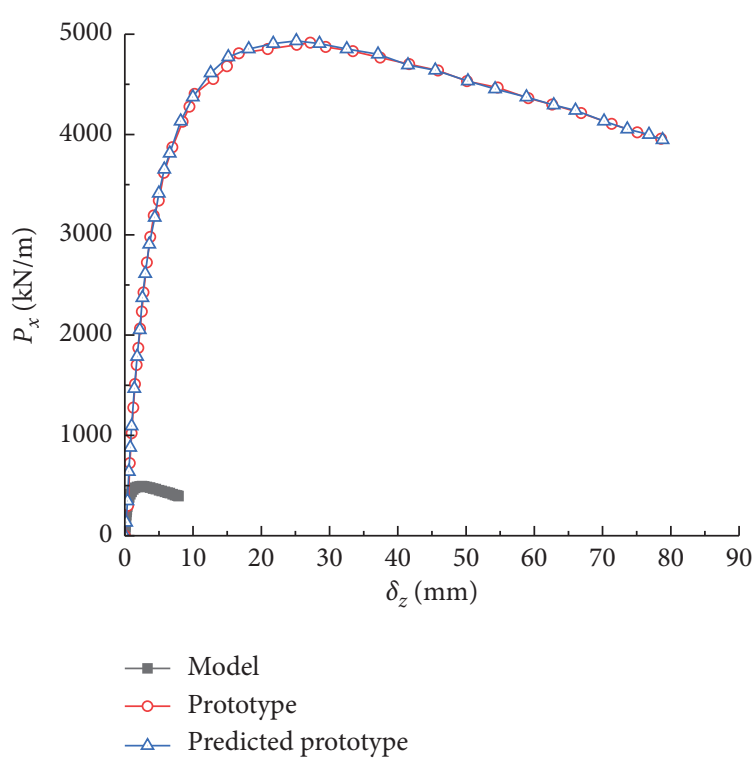

(b)

FIgUre 4: Continued. 


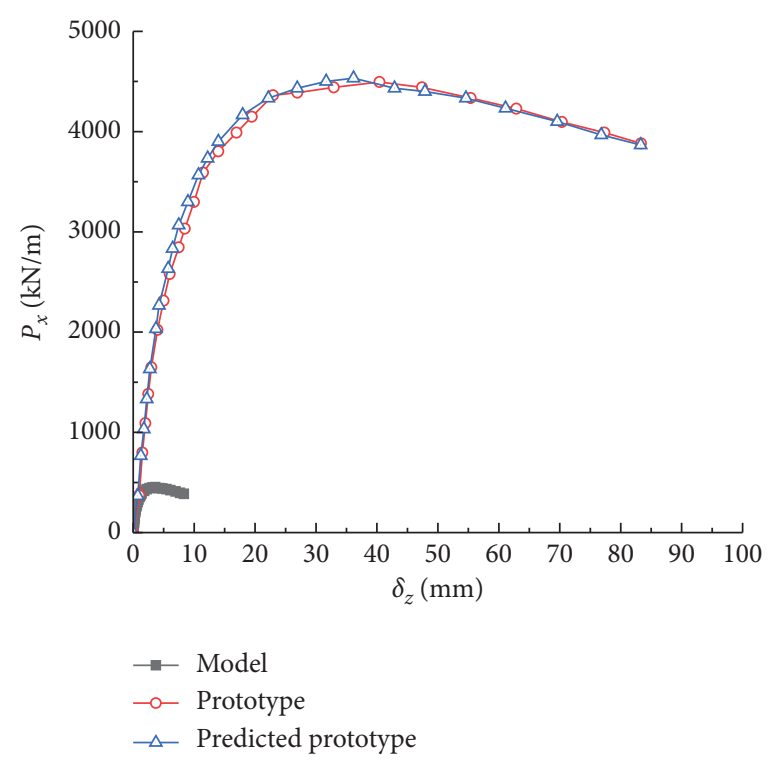

(c)

Figure 4: Comparison of complete similitude load-displacement curves for nonlinear buckling of the stiffened cylindrical shell under axial compression when $\lambda_{\mathrm{p}}=0.72 \mathrm{~m}$ and $\lambda_{\mathrm{m}}=0.072 \mathrm{~m}$. (a) $\delta 0=0.1 \bar{t}$. (b) $\delta 0=0.3 \bar{t}$. (c) $\delta 0=0.5 \bar{t}$.

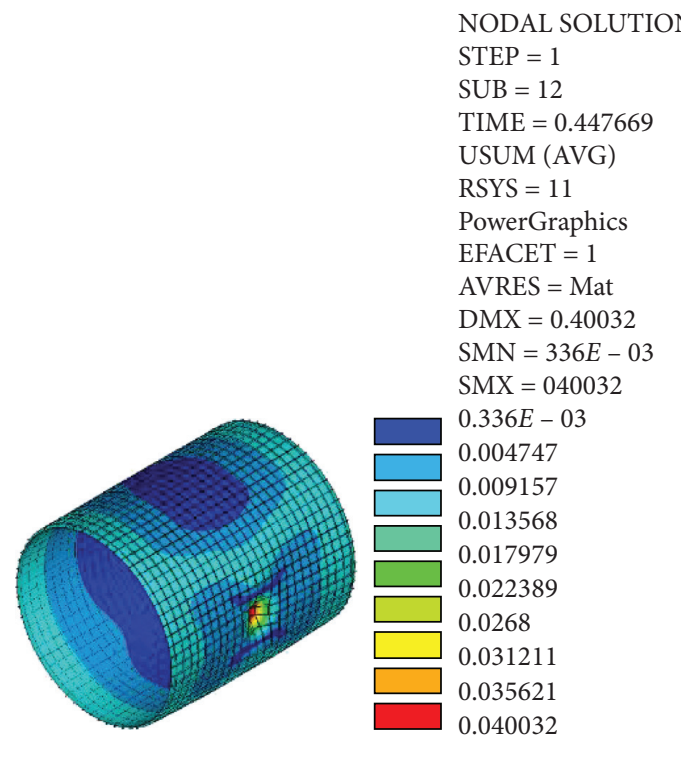

(a)

NODAL SOLUTION
STEP $=1$
SUB $=12$
TIME $=0.447669$
USUM $($ AVG)
RSYS $=11$
PowerGraphics
EFACET $=1$
AVRES $=$ Mat
DMX $=0.40032$
SMN $=336 E-03$
SMX $=040032$
$0.336 E-03$
0.004747
0.009157
0.013568
0.017979
0.022389
0.0268
0.031211
0.035621
0.040032

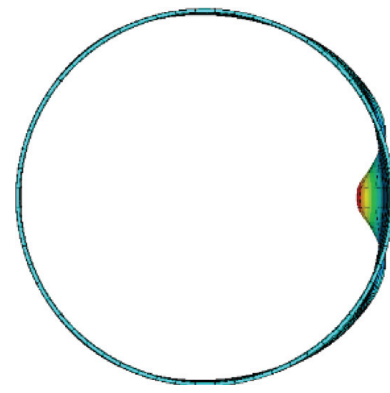

NODAL SOLUTION

$\mathrm{STEP}=1$

$\mathrm{SUB}=12$

TIME $=0.447669$

USUM (AVG)

RSYS $=11$

PowerGraphics

EFACET $=1$

AVRES $=$ Mat

$\mathrm{DMX}=0.40032$

$\mathrm{SMN}=0.336 E-03$

$\mathrm{SMX}=0.40032$

$0.336 E-034$

0.004747

0.009157

0.013568

0.017979

0.022389

0.0268

0.031211

0.035621

0.040032

Figure 5: Continued.

(b) 


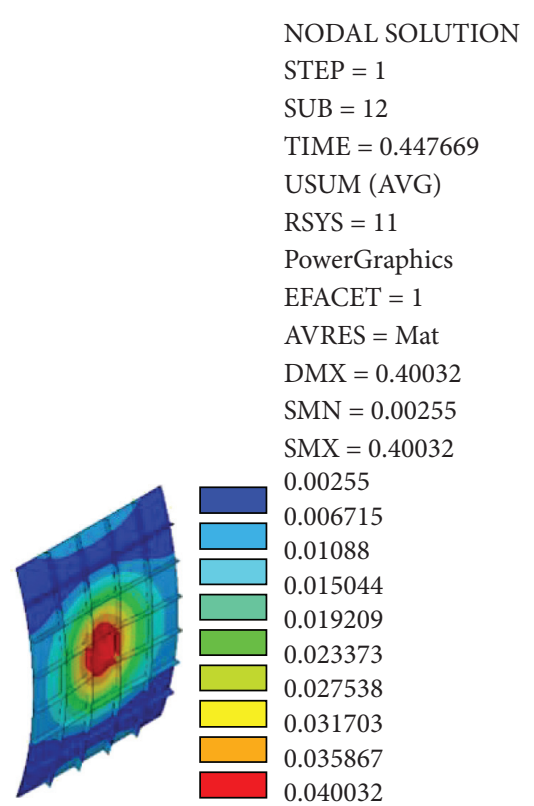

(c)

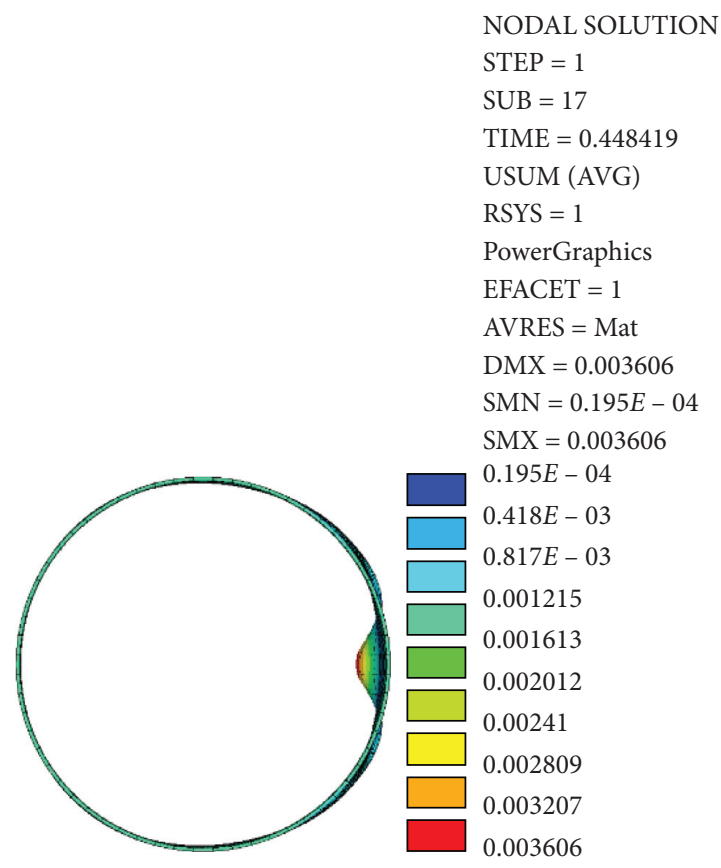

(e)

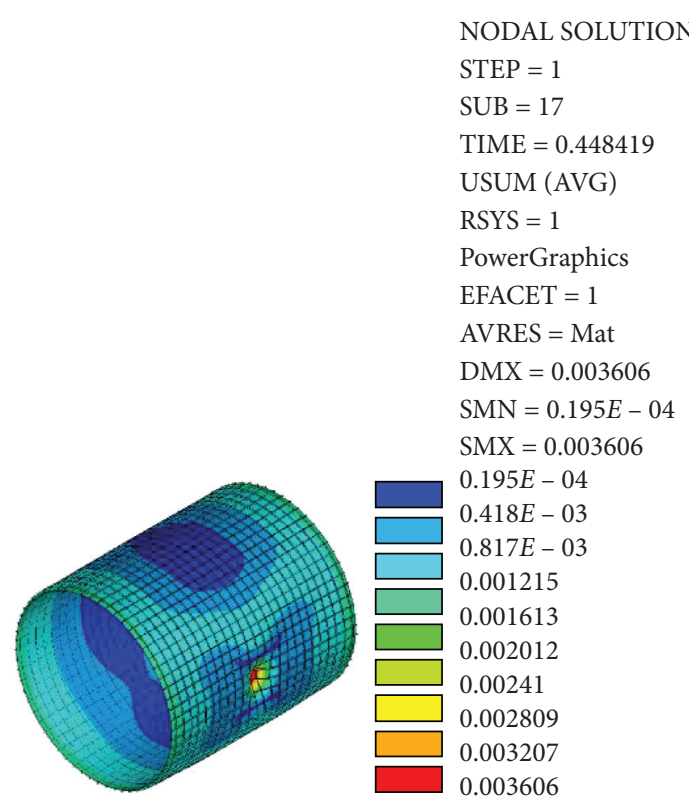

(d)
NODAL SOLUTION
STEP $=1$
$\mathrm{SUB}=17$
TIME $=0.448419$
USUM (AVG)
RSYS $=1$
PowerGraphics
EFACET $=1$
AVRES $=$ Mat
DMX $=0.003606$
$\mathrm{SMN}=206 E-04$
SMX $=0.003606$
$0.206 E-03$
$0.583 E-03$
$0.961 E-03$
0.001339
0.001717
0.002095
0.002472
0.00285
0.003228
0.003606

(f)

Figure 5: Comparison of buckling modes between the prototype and complete similitude model when $\lambda_{\mathrm{p}}=0.720 \mathrm{~m}, \lambda_{\mathrm{m}}=0.072 \mathrm{~m}$, and $\delta_{0}=0.5 \bar{t}$. (a) Oblique view of the prototype (10x magnification). (b) Front view of the prototype (10x magnification). (c) Near imperfection of the prototype (1x). (d) Oblique view of the model (10x magnification). (e) Front view of the model (10x magnification). (f) Near imperfection of the model $(1 \mathrm{x})$.

TABLE 6: Material parameters of the scale model.

\begin{tabular}{lcc}
\hline Material & $E(\mathrm{GPa})$ & $\mu$ \\
\hline Aluminum & 68.75 & 0.30 \\
Copper & 124 & 0.33 \\
Brass & 106 & 0.34 \\
PVC & 3.79 & 0.40 \\
\hline
\end{tabular}


TABLE 7: Partial similitude simulation of axial compression nonlinear buckling of the longitudinal-ring rectangular stiffened cylindrical shell.

\begin{tabular}{|c|c|c|c|c|c|}
\hline \multirow{2}{*}{$\delta_{0}(\mathrm{~m})$} & \multirow{2}{*}{ Material } & \multicolumn{3}{|c|}{ Critical buckling load $\left(\mathrm{kN} \cdot \mathrm{m}^{-1}\right)$} & \multirow{2}{*}{ Error $(\%)$} \\
\hline & & Model & Prototype & Prediction prototype & \\
\hline $0.1 \bar{t}$ & \multirow{3}{*}{ Aluminum } & 595.318 & 6224.06 & 6269.24 & 0.73 \\
\hline $0.3 \bar{t}$ & & 500.759 & 5273.95 & 5273.45 & -0.01 \\
\hline $0.5 \bar{t}$ & & 454.787 & 4810.45 & 4789.32 & -0.43 \\
\hline $0.1 \bar{t}$ & \multirow{3}{*}{ Copper } & 1055.31 & 6224.06 & 6033.68 & -3.06 \\
\hline $0.3 \bar{t}$ & & 898.381 & 5273.95 & 5136.44 & -2.60 \\
\hline $0.5 \bar{t}$ & & 812.553 & 4810.45 & 4645.73 & -3.42 \\
\hline $0.1 \bar{t}$ & \multirow{3}{*}{ Brass } & 900.281 & 6224.06 & 5976.10 & -3.98 \\
\hline $0.3 \bar{t}$ & & 767.129 & 5273.95 & 5092.24 & -3.45 \\
\hline $0.5 \bar{t}$ & & 692.715 & 4810.45 & 4598.27 & -4.41 \\
\hline $0.1 \bar{t}$ & \multirow{3}{*}{ PVC } & 32.182 & 6224.06 & 5674.80 & -8.83 \\
\hline $0.3 \bar{t}$ & & 27.270 & 5273.95 & 4808.64 & -8.82 \\
\hline $0.5 \bar{t}$ & & 24.951 & 4810.45 & 4399.72 & -8.54 \\
\hline
\end{tabular}
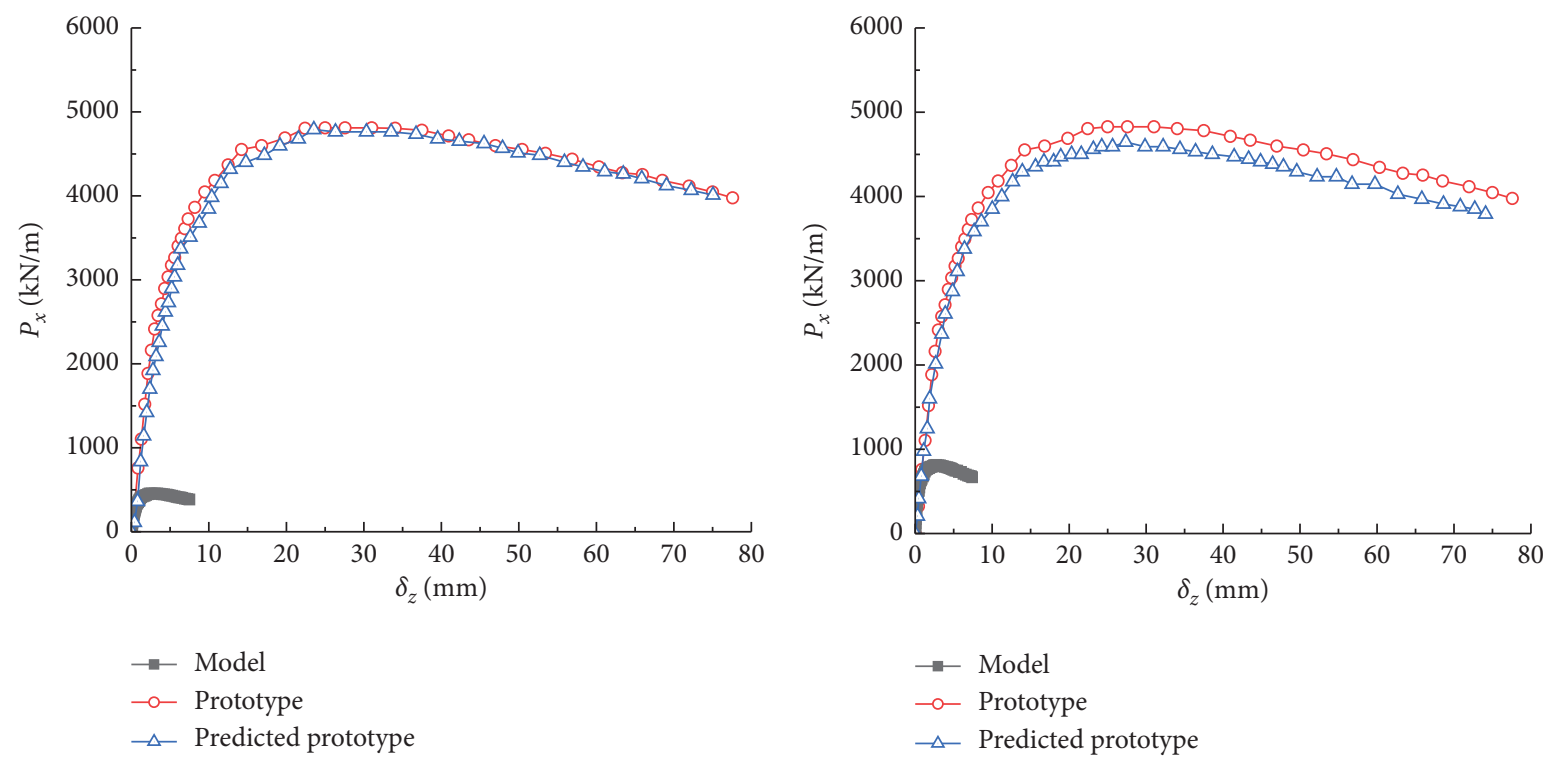

(a)

(b)

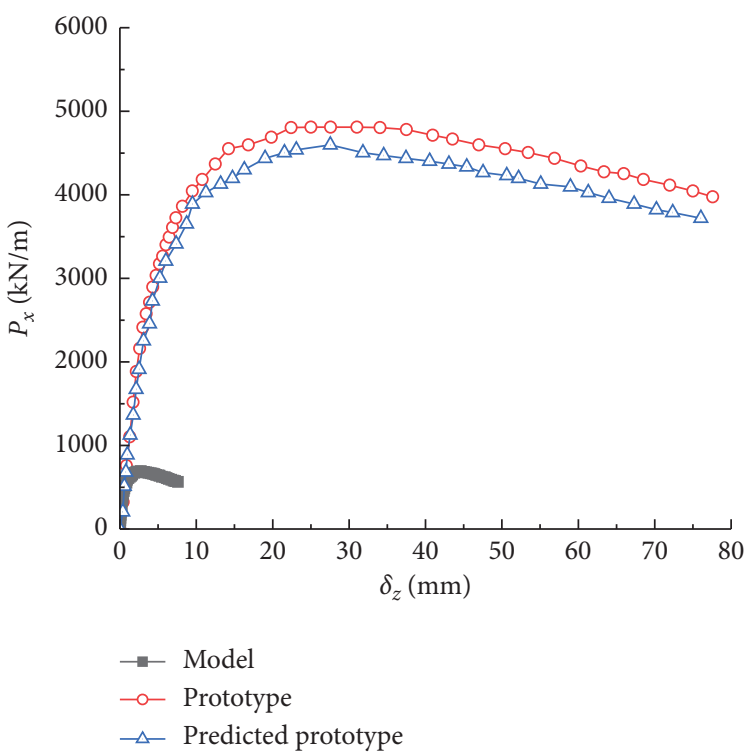

(c)

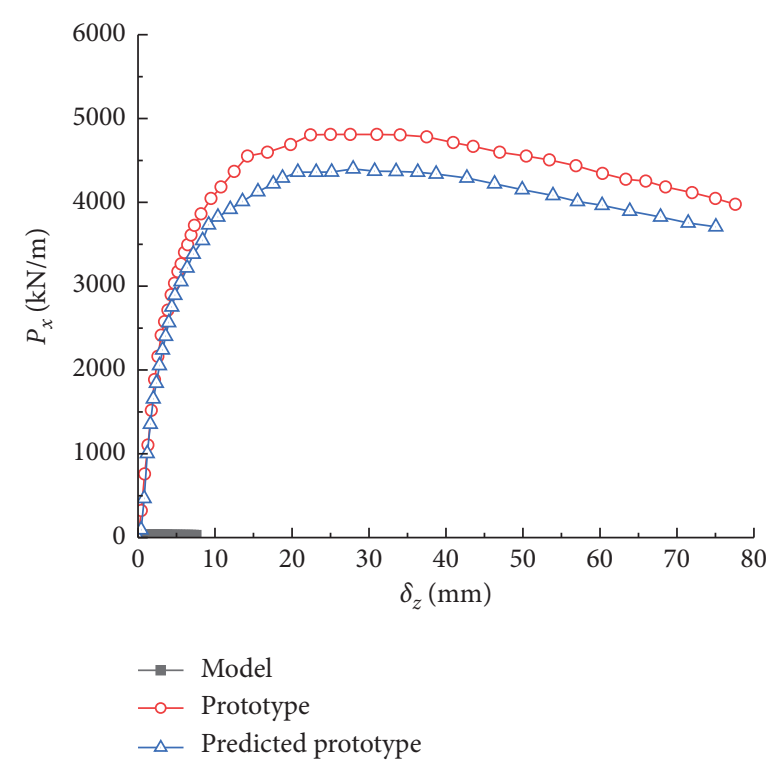

(d)

FIGURE 6: Comparison of partial similitude load-displacement curves for axial compression nonlinear buckling of the stiffened cylindrical shell when $\delta_{0}=0.5 \bar{t}$. (a) The model material is aluminum. (b) The model material is copper. (c) The model material is brass. (d) The model material is PVC. 


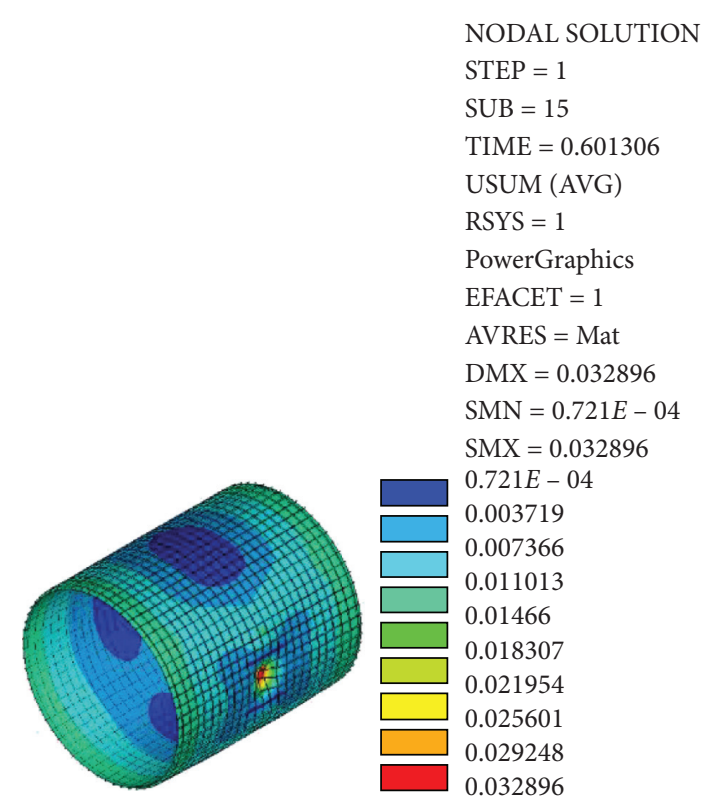

(a)

NODAL SOLUTION

STEP $=1$

SUB $=15$

TIME $=0.601306$

USUM (AVG)

RSYS $=1$

PowerGraphics

EFACET $=1$

AVRES $=$ Mat

DMX $=0.032896$

$\mathrm{SMN}=0.001608$

SMX $=0.032896$

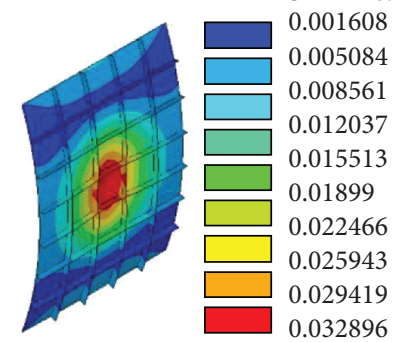

(c)
NODAL SOLUTION

STEP $=1$

$\mathrm{SUB}=15$

TIME $=0.601306$

USUM (AVG)

RSYS $=1$

PowerGraphics

EFACET $=1$

AVRES $=$ Mat

DMX $=0.032896$

$\mathrm{SMN}=0.721 E-04$

SMX $=0.032896$

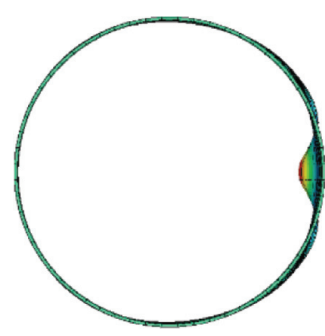

$0.721 E-04$

0.003719

0.007366

0.011013

0.01466

0.018307

0.021954

0.025601

0.029248

0.032896

(b)

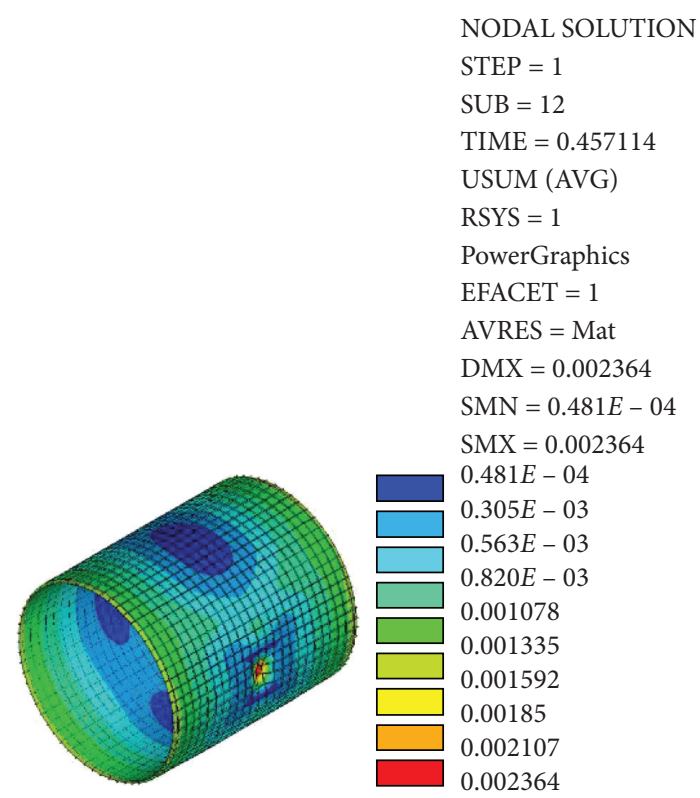

(d)

Figure 7: Continued. 


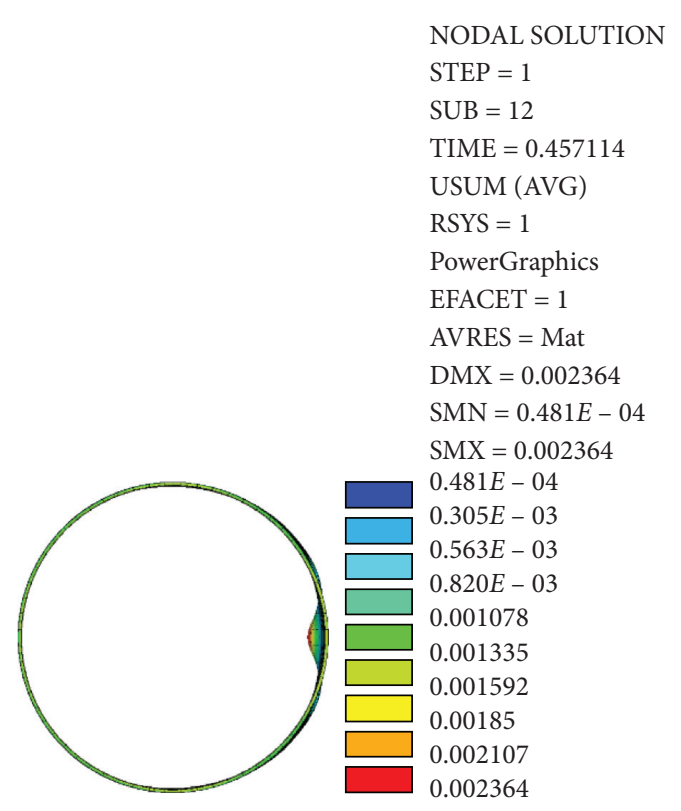

(e)

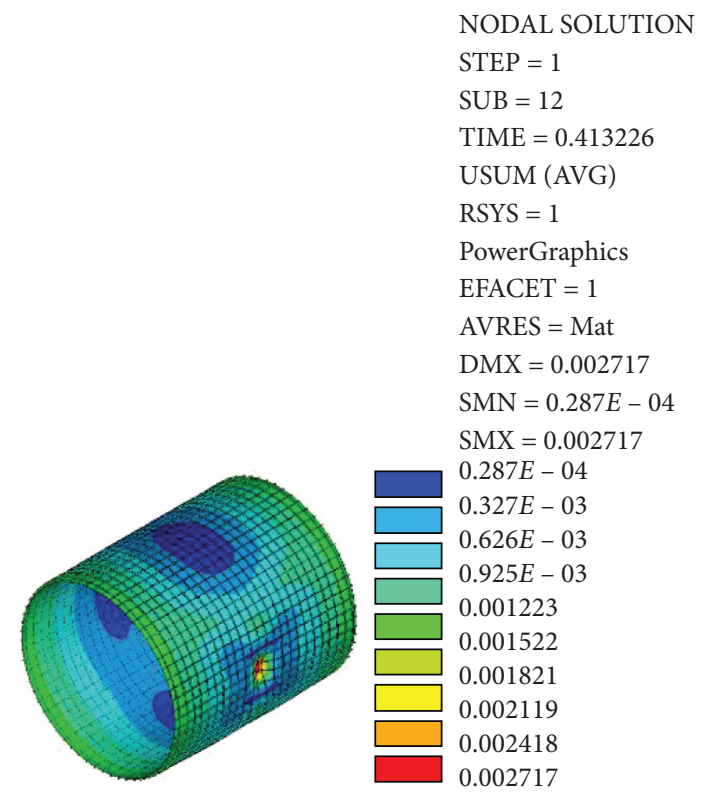

(g)

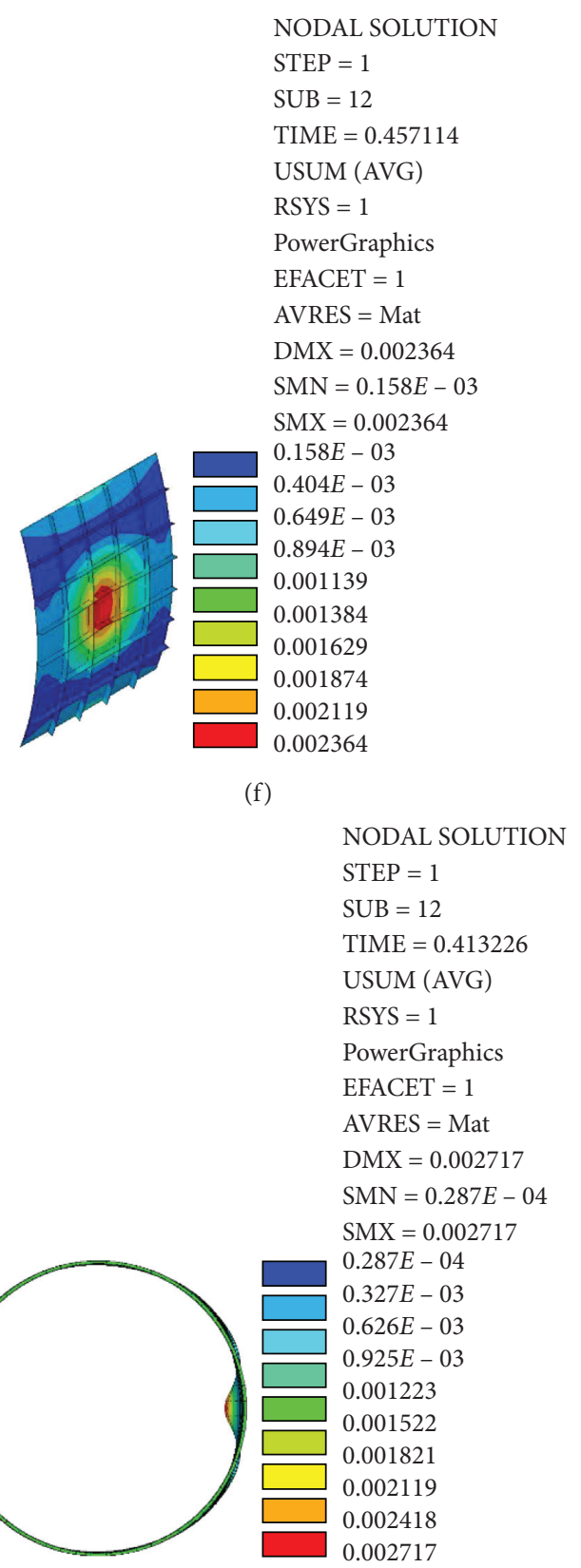

(h)

Figure 7: Continued. 


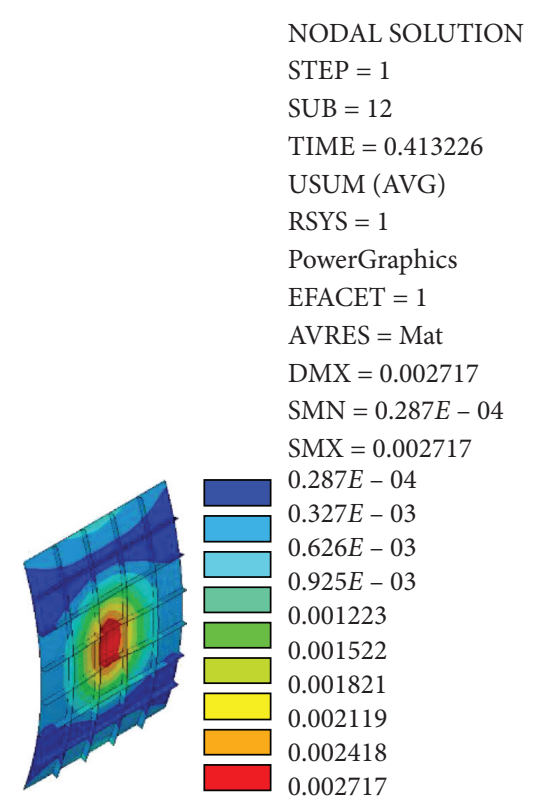

(i)

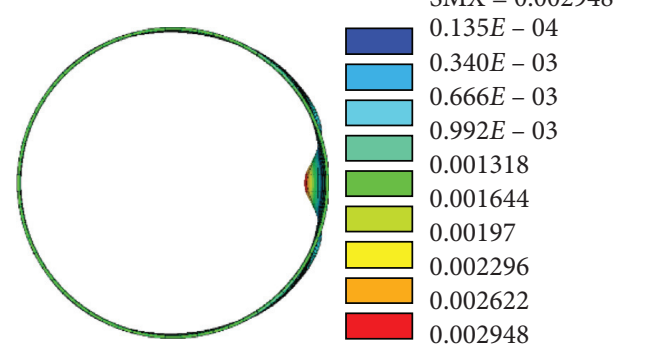

(k)

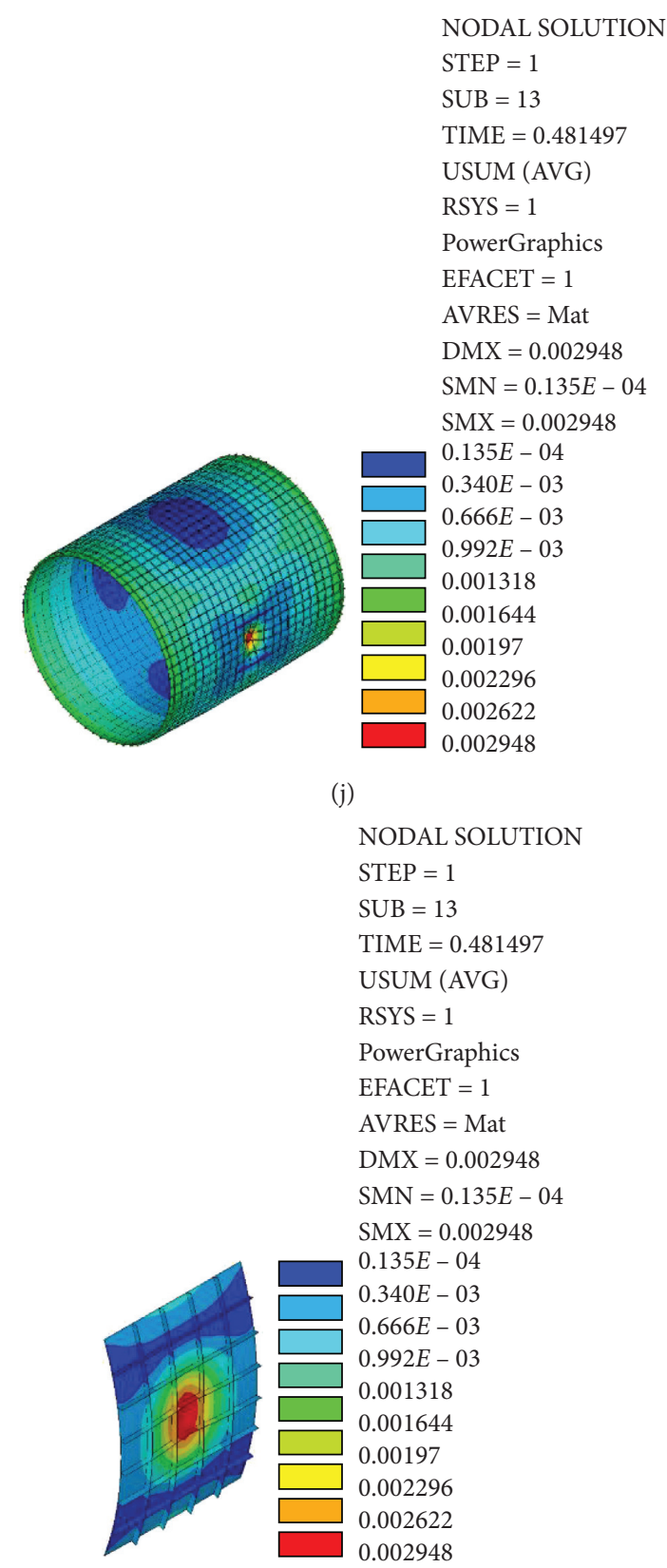

(1)

Figure 7: Continued. 


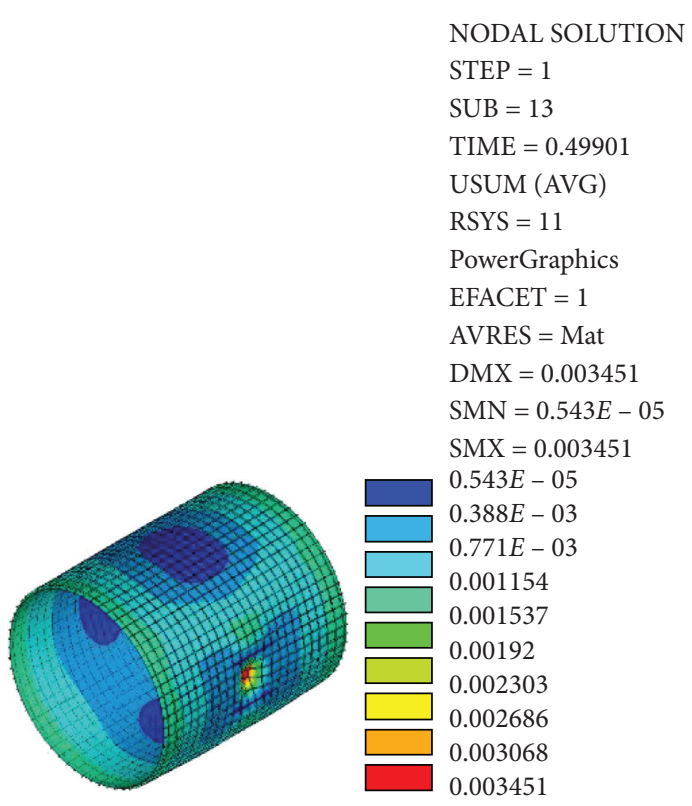

$(\mathrm{m})$

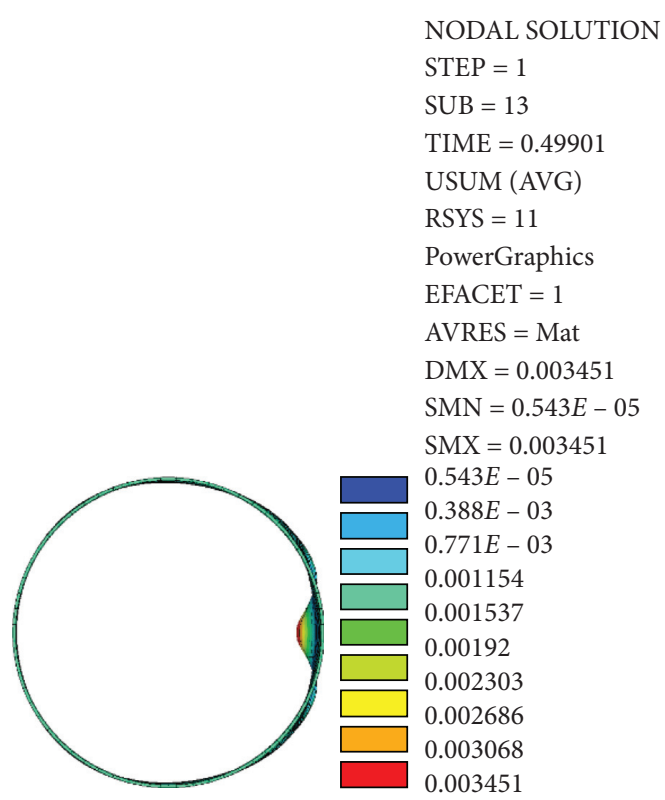

(n)

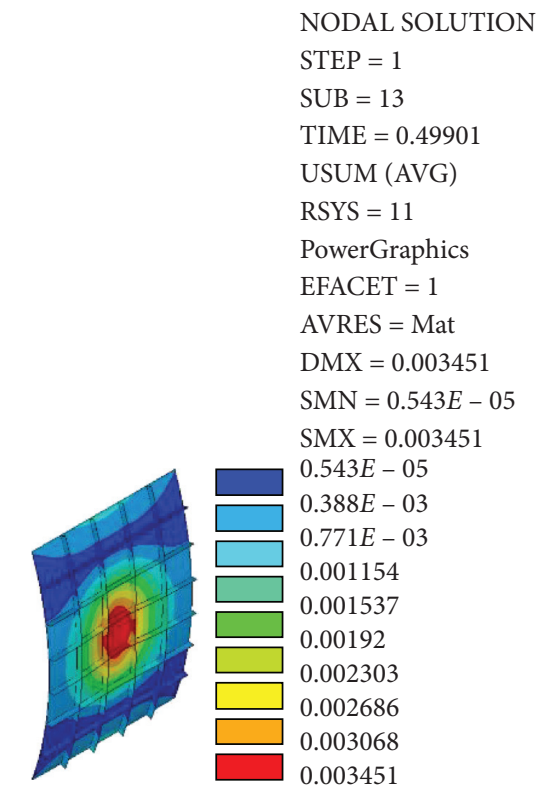

(o)

Figure 7: Comparison of buckling modes between the prototype and partial similitude model when $\lambda_{\mathrm{m}}=0.060 \mathrm{~m}$ and $\delta_{0}=0.5 \bar{t}$. (a) Oblique view of the prototype (10x magnification). (b) Front view of the prototype (10x magnification). (c) Near imperfection of the prototype (1x). (d) Oblique view of the aluminum model (10x magnification). (e) Front view of the aluminum model (10x magnification). (f) Near imperfection of the aluminum model $(1 \mathrm{x})$. (g) Oblique view of the copper model (10x magnification). (h) Front view of the copper model (10x magnification). (i) Near imperfection of the copper model (1x). (j) Oblique view of the brass model (10x magnification). (k) Front view of the brass model (10x magnification). (l) Near imperfection of the brass model (1x). (m) Oblique view of the PVC model (10x magnification). (n) Front view of the PVC model (10x magnification). (o) Near imperfection of the PVC model (1x). 


$$
\begin{aligned}
C_{A_{r}} & =k_{1}^{2}, \\
C_{I_{r}} & =C_{J_{r}}=k_{1}^{4}, \\
C_{e_{r}} & =k_{1}, \\
C_{A_{s}} & =k_{1}^{2}, \\
C_{I_{s}} & =C_{J_{s}}=k_{1}^{4}, \\
C_{e_{s}} & =k_{1}, \\
C_{\text {stiff }} & =k k_{1}^{3} \frac{1-\mu_{m}^{2}}{1-\mu_{p}^{2}} .
\end{aligned}
$$

Therefore, by simplifying formula (11), we can get the scaling principle formula of the partial similitude of the longitudinal-ring rectangular stiffened cylindrical shell buckling under axial compression, which is

$$
C_{\bar{p}_{x}}=k k_{1} \frac{1-\mu_{m}^{2}}{1-\mu_{p}^{2}} .
$$

5.2. Example Analysis on Partial Similitude of Axial Compression Nonlinear Buckling of the Longitudinal-Ring Rectangular Stiffened Cylindrical Shell. Taking the skin geometric scaling factor $k_{1}$ as 10 and solving equation sets (15) and (16), respectively, the geometric dimensions of circumferential and longitudinal stiffeners of the partial similitude scale model can be obtained, namely, $h_{\mathrm{rm}}=h_{\mathrm{sm}}=3.8354 \mathrm{~mm}$ and $t_{\mathrm{rm}}=t_{\mathrm{sm}}=2.4384 \mathrm{~mm}$. It can be seen that the geometric scaling factor of stiffeners is equal to that of the skin.

Taking the dimple imperfection diameter of $0.060 \mathrm{~m}$ as an example, under three imperfection amplitudes of $0.1 \bar{t}$, $0.3 \bar{t}$, and $0.5 \bar{t}$, the arc-length method in finite element analysis was used to study the partial similitude of axial compression nonlinear buckling of the longitudinal-ring stiffened cylindrical shell for the partial similitude models made of four materials.

It can be seen from Table 7 that, for the scale model made of aluminum under three working conditions consisting of three imperfection amplitudes, the absolute value of the relative error between the critical load of the prototype structure predicted by the scale model based on scaling principle formula (19) and the critical load of the prototype structure is within $1.00 \%$. With the increase of Poisson's ratio deviation between the scale model and prototype, the relative error of critical load between the prediction prototype structure and the prototype structure increases. When the scale model is made of PVC, the relative error between the critical load of the prediction prototype structure and that of the prototype structure reaches $-8.83 \%$.

Figure 6 shows the load-displacement curves of the prototype, the four partial similitude scale models, and their corresponding prediction prototypes when the dimple imperfection diameter is $0.060 \mathrm{~m}$ and the imperfection amplitude is $0.5 \bar{t}$. Figure 7 shows the displacement vector and nephogram at the points corresponding to the critical buckling loads of the structural prototype and the partial similitude scale models made of four materials when the imperfection amplitude is $0.5 \bar{t}$. It can be seen that, for the partial similitude model made of $\mathrm{Al}$, the load-displacement curve of its prediction prototype can accurately predict the load-displacement curve of the prototype structure; the critical buckling load error between the prediction prototype and the prototype is $-0.43 \%$; the buckling modes of the model and the prototype at the point corresponding to critical buckling load are the same. With the increase of Poisson's ratio deviation between the partial similitude scale model and the prototype, the deviation of the load-displacement curve between the prediction prototype and prototype increases gradually. For the scale models made of copper, brass, and PVC, the critical buckling load errors between their prediction prototypes and prototypes are $-3.42 \%,-4.41 \%$, and $-8.54 \%$, respectively. The buckling modes of the scale models of the three materials are consistent with those of the prototypes.

\section{Conclusions}

In this paper, the longitudinal-ring rectangular stiffened cylindrical shell is taken as the research object; a scaling finite element model of the stiffened cylindrical shell with dimple imperfections is designed and established according to the generalized similitude conditions and scaling principle formula derived by the energy method, and the nonlinear buckling analysis of structural complete similitude and partial similitude under axial compression is also carried out. The following are the conclusions obtained:

(a) The axial compression nonlinear buckling results of the stiffened cylindrical shell complete the similitude scale model that can accurately predict the buckling characteristics of the prototype structure by combining with the corresponding scaling principle formula, which shows that the generalized similitude conditions and scaling principle formula of structural axial-compression nonlinear buckling complete similitude are correct.

(b) The prediction prototype results obtained from the axial compression nonlinear buckling of the stiffened cylindrical shell partial similitude scale model can better predict the buckling characteristics of prototype structures, which shows that the generalized similitude conditions and scaling principle formula of structural axial-compression partial similitude have better accuracy. Meanwhile, the results also show that when the geometric parameters and material parameters are different, the greater the deviation of Poisson's ratio between the model and the prototype, the greater the error of the calculated results and the worse the coincidence of the loaddisplacement curves. Therefore, when designing the scale model, the material of the model should be selected as close as possible to Poisson's ratio of the 
prototype material, and the analogue prediction of structural axial-compression nonlinear buckling characteristics should be carried out.

(c) The generalized similitude conditions and scaling principle formulas of the axial compression nonlinear buckling of stiffened cylindrical shells with dimple imperfections established in this paper can provide a useful reference for the safety assessment of the axial compression nonlinear buckling of similar large-size stiffened cylindrical shells in practical engineering and have certain practical application value.

(d) In this study, the material of the structure is regarded as linear elastic. However, plastic buckling is prone to occur in stiffened shells in some cases. So whether the proposed method is suitable for structures considering material nonlinearity and plastic buckling needs further study. In addition, we have noticed some studies [20-22] on nano/microstructure. So it is also worth studying to analyze the scaled nano/microshells and plates with methods of this paper.

\section{Data Availability}

The original data required by the fund project cannot be made public and can be made available from the corresponding author upon request.

\section{Conflicts of Interest}

The authors declare that they have no conflicts of interest.

\section{Acknowledgments}

This work was supported by the National Natural Science Foundation of China (Grant no. 51868013), Natural Science Foundation of Guangxi Province (Grant nos. 2018GXNSFBA138056 and 2018GXNSFAA050145), Guangxi Innovation-Driven Development Special Project (Grant no. GuiKe AA18118008), Science and Technology Project of Guangxi (Grant no. Guike AD19245127), and Doctoral Research Initiation Fund of Guilin University of Technology (Grant no. GUTQDJJ2017034). The authors are grateful for these financial supports.

\section{References}

[1] B. Wang, P. Hao, and K. Tian, "Recent advances in structural analysis and optimization of stiffened shells," Chinese Journal of Computational Mechanics, vol. 36, no. 1, pp. 1-12, 2019.

[2] P. Qiao, Y. Wang, and L. Lu, "Advances in stability study of cylindrical shells," Chinese Quarterly of Mechanics, vol. 39, no. 2, pp. 223-236, 2018.

[3] G. J. Simitses, J. Rezaeepazhand, and R. L. Sierakowski, "Scaled models for laminated cylindrical shells subjected to external pressure," Mechanics of Advanced Materials and Structures, vol. 4, no. 3, pp. 267-280, 1997.

[4] V. Ungbhakorn and P. Singhatanadgid, "Scaling law and physical similitude for buckling and vibration of antisymmetric angle-ply laminated cylindrical shells," International Journal of Structural Stability and Dynamics, vol. 3, no. 4, pp. 567-583, 2003.

[5] V. Ungbhakorn and P. Singhatanadgid, "Similitude and physical modeling for buckling and vibration of symmetric cross-ply laminated circular cylindrical shells," Journal of Composite Materials, vol. 37, no. 19, pp. 1697-1712, 2003.

[6] M. W. Hilburger, W. T. Haynie, A. E. Lovejoy et al., "Subscale and full-scale testing of buckling-critical launch vehicle shell structures," in Proceedings of the 53rd AIAA/ASME/ASCE/ AHS/ASC Structures, Structural Dynamics and Materials Conference $<B R>$ 20th, pp. 1-33, Honolulu, HI, USA, 2012.

[7] M. W. Hilburger, A. E. Lovejoy, R. P. Thornburgh et al., "Design and analysis of subscale and full-scale bucklingcritical cylinders for launch vehicle technology development," in Proceedings of the 53rd AIAA/ASME/ASCE/AHS/ASC Structures, Structural Dynamics and Materials Conference $<B R>$ 20th, pp. 1-48, Honolulu, HI, USA, 2012.

[8] I. U. Balbin and C. Bisagni, "Scaling methodology applied to buckling of sandwich composite cylindrical shells," in Proceedings of the 2018 AIAA/ASCE/AHS/ASC Structures, Structural Dynamics, and Materials Conference, Kissimmee, FL, USA, 2012.

[9] W. Yu, "Study on nonlinear buckling and stability of new-type dry gas holder structure," Chongqing: Doctoral thesis, Chongqing University, Chongqing, China, 2016.

[10] K. Tian, B. Wang, P. Hao, and A. M. Waas, "A high-fidelity approximate model for determining lower-bound buckling loads for stiffened shells," International Journal of Solids and Structures, vol. 148-149, p. 14, 2018.

[11] H. N. R. Wagner, C. Hühne, and S. Niemann, "Buckling of launch-vehicle cylinders under axial compression: a comparison of experimental and numerical knockdown factors," Thin-Walled Structures, vol. 155, Article ID 106931, 2020.

[12] K. Tian, L. Huang, Y. Sun, K. Du, P. Hao, and B. Wang, "Fast buckling load numerical prediction method for imperfect shells under axial compression based on POD and vibration correlation technique," Composite Structures, vol. 252, Article ID 112721, 2020.

[13] W. T. Haynie and M. W. Hilburger, "Comparison of methods to predict lower bound buckling loads of cylinders under axial compression," in Proceedings of the 51st AIAA/ASME/ASCE/ AHS/ASC Structures Structural Dynamics and Materials Conference $<B R>18$ th, pp. 1-22, Orlando, FL, USA, 2010.

[14] V. Ungbhakorn and P. Singhatanadgid, "A scaling law for vibration response of laminated doubly curved shallow shells by energy approach," Mechanics of Advanced Materials and Structures, vol. 16, no. 5, pp. 333-344, 2009.

[15] M. Amabili, Nonlinear Vibrations and Stability of Shells and Plates, Cambridge University Press, New York, NY, USA, 2008.

[16] Plate and Shell Group, Laboratory of Solid Mechanics, Chinese Academy of Sciences, Stiffened Cylindrical Curved Plate and Cylindrical Shell, Science Press, Beijing, China, 1983.

[17] E. Ventsel and T. Krauthammer, Thin Plates and Shells: Theory, Analysis, and Applications, Marcel Dekker Inc., New York, NY, USA, 2001

[18] J. A. Mcelman, M. M. Mikulas Jr., and M. Stein, "Static and dynamic effects of eccentric stiffening of plates and cylindrical shells," AIAA Journal, vol. 4, no. 5, pp. 887-894, 1966.

[19] B. Wang, P. Hao, G. Li, Y. Fang, X. Wang, and X. Zhang, "Determination of realistic worst imperfection for cylindrical shells using surrogate model," Structural and Multidisciplinary Optimization, vol. 48, no. 4, pp. 777-794, 2013. 
[20] M. H. Jalaei and Ö. Civalek, "On dynamic instability of magnetically embedded viscoelastic porous FG nanobeam," International Journal of Engineering Science, vol. 143, pp. 14-32, 2019.

[21] Ö. Civalek, S. Dastjerdi, S. D. Akbas, and B. AkgÖz, "Vibration analysis of carbon nanotube-reinforced composite microbeams," Mathematical Method in the Applied Science, pp. 1-17, 2021.

[22] S. Dastjerdi, B. Akgöz, and Ö. Civalek, "On the effect of viscoelasticity on behavior of gyroscopes," International Journal of Engineering Science, vol. 149, 2020. 